\title{
Randomised phase II trial of gemcitabine plus vinorelbine vs gemcitabine plus cisplatin vs gemcitabine plus capecitabine in patients with pretreated metastatic breast cancer
}

\author{
HJ Stemmler, , D diGioia', W Freier ${ }^{2}$, HW Tessen ${ }^{3}$, G Gitsch ${ }^{4}$, W Jonat ${ }^{5}$, W Brugger ${ }^{6}$, E Kettner ${ }^{7}$, \\ W Abenhardt ${ }^{8}$, H Tesch', HJ Hurtz ${ }^{10}$, S Rösel '1, O Brudler' ${ }^{12}$ and V Heinemann' \\ 'Med. Department III, Ludwig-Maximilians University of Munich, Campus Grosshadern, Munich, Germany; ${ }^{2}$ Oncological Practice, Hildesheim, Germany; \\ ${ }^{3}$ Oncological Practice, Goslar, Germany; ${ }^{4}$ Department of Gynaecology \& Obstetrics, University of Freiburg, Freiburg, Germany; ${ }^{5}$ Department of \\ Gynaecology \& Obstetrics, University of Kiel, Kiel, Germany; ${ }^{6}$ Med. Department II, Clinical Centre Villingen-Schwenningen, Villingen-Schwenningen, \\ Germany; ${ }^{7}$ Department of Hematology \& Oncology, Clinical Centre Magdeburg, Magdeburg, Germany; ${ }^{8}$ Oncological Practice, Munich, Germany; \\ ${ }^{9}$ Oncological Practice, Frankfurt, Germany; ${ }^{10}$ Oncological Practice, Halle, Germany; ${ }^{11}$ Oncological Practice, Gütersloh, Germany; ${ }^{12}$ Oncological Practice, \\ Augsburg, Germany
}

BACKGROUND: An increasing proportion of patients are exposed to anthracyclines and/or taxanes in the adjuvant or neoadjuvant setting. Re-exposure in the metastatic stage is limited by drug resistance, thus evaluation of non-cross-resistant regimens is mandatory. METHODS: Anthracycline-pretreated patients were randomly assigned to three gemcitabine-based regimens. Chemotherapy consisted of gemcitabine $1.000 \mathrm{mg} \mathrm{m}^{-2}$ plus vinorelbin $25 \mathrm{mgm}^{-2}$ on days I +8 (GemVin), or plus cisplatin $30 \mathrm{mg} \mathrm{m}^{-2}$ on days I +8 (GemCis), or plus capecitabine $650 \mathrm{mg} \mathrm{m}^{-2}$ b.i.d. orally days I- 14 (GemCap), q3w. The primary end point was response rate. RESULTS: A total of I 4 I patients were recruited on the trial. The overall response rates were 39.0\% (GemVin), 47.7\% (GemCis) and 34.7\% (GemCap). Median progression-free survival was estimated with 5.7, 6.9 and 8.3 months, respectively. Corresponding median survival times were 17.5 (GemVin), 13.0 (GemCis) and 19.4 months (GemCap). Neutropenia $\geqslant$ grade 3 occurred in $16.7 \%$ (Gem/Vin), 4.4\% (GemCis) and 0\% (Gem/Cap), whereas non-haematological toxicities were rarely severe except grade 3 hand-foot syndrome in $2.0 \%$ of the GemCap patients (per patient analysis).

CONCLUSIONS: This randomised phase II trial has revealed comparable results for three gemcitabine-based regimens regarding treatment efficacy and toxicity. Gemcitabine-based chemotherapy appears to be a worthwhile treatment option for pretreated patients with metastatic breast cancer.

British Journal of Cancer (201I) 104, I07I-1078. doi:I0.1038/bjc.201।.86 www.bjcancer.com

Published online I5 March 201।

(c) 2011 Cancer Research UK

Keywords: gemcitabine; cisplatin; vinorelbine; capecitabine; anthracycline resistance; metastatic breast cancer

Strategies in patients with advanced breast cancer are confounded by the increasing exposure of patients to chemotherapy in the adjuvant setting. Nevertheless, two general strategies are apparent and should be followed: (1) improving treatment efficacy by exploring new drugs and drug combinations, and (2) ensuring that efficacy is improved with the lowest cost to quality of life.

Gemcitabine as a single agent has induced overall response rates of $0-37 \%$ in first-line treatment, whereas the response rates in the second- or third-line therapy were 26 and $13 \%$ (Brodowicz et al, 2000; Spielmann et al, 2001; Blackstein et al, 2002; Heinemann, 2003, 2005; Modi et al, 2005). In studies limited to second- or third-line therapy after anthracycline and/or taxane exposure, response rates of $0-29 \%$ and median time to progression of 2-6 months were achieved (Spielmann et al, 2001; Modi et al, 2005;

*Correspondence: Priv. Doz. Dr HJ Stemmler; E-mail: Joachim.Stemmler@med.uni-muenchen.de

Received 23 November 2010; revised II February 2011; accepted 2I February 20 I ; published online I5 March 20 I I
Heinemann et al, 2006; Seo et al, 2007). Several considerations support the use of gemcitabine and a platinum salt in the salvage treatment of metastatic breast cancer (MBC): First, in vitro studies indicate additive or synergistic activity that was most pronounced in platinum-resistant cell lines and was found to be due to an increased formation and an impaired repair of platinum-DNA adducts (Peters et al, 1995; van Moorsel et al, 1997). Second, gemcitabine and the platinum salts are usually not included into adjuvant or neoadjuvant chemotherapy. Therefore, resistance to either drug is unlikely to occur. Third, studies investigating the combination have shown minimal overlapping toxicity, suggesting an acceptable toxicity profile even in intensively pretreated patients. The combination of gemcitabine and cisplatin was shown to be effective in several trials, inducing response rates between 30 and $52 \%$ in patients pretreated with taxanes and/or anthracyclines (Kolaric and Vukas, 1991; Chitapanarux et al, 2006; Fuentes et al, 2006; Heinemann et al, 2006; Kim et al, 2008).

Vinorelbine has shown good efficacy as first-line treatment $(40-60 \%)$, activity after anthracycline pretreatment has only been moderate (16\%) (Degardin et al, 1994; Jones et al, 1995; 
Gregory and Smith, 2000). The dose-limiting toxicity of vinorelbine is in the form of non-cumulative haematotoxicity. The potential of adding gemcitabine to vinorelbine has been explored in various phase II studies (Nicolaides et al, 2000; Valenza et al, 2000; Park et al, 2009; Shehata et al, 2010). Haider et al (1999) conducted a study that evaluated gemcitabine plus vinorelbine (GemVin) separately as first-line therapy. In the subgroup of 45 chemonaive patients the overall response rate was $56 \%$. Two additional studies that applied GemVin for second-line therapy (after anthracyclines \pm taxanes) achieved response rates of 48 and 54\%, respectively (Haider et al, 1999; Valenza et al, 2000; Stathopoulos et al, 2002; Shehata et al, 2010). These studies demonstrate that the combination of GemVin is active not only as first-line treatment but also after pretreatment with anthracyclineor anthracycline/taxane-based regimens. Gemcitabine and capecitabine (GemCap) are among the few agents active in patients with MBC progressing after therapy with anthracyclines and taxanes. Andres et al (2005) conducted a phase II trial of GemCap in patients with disease progression after treatment with anthracyclines and taxanes. The response rate was $48.7 \%$. Median time to progression was 5 months (range, 1-26 months) and the median overall survival duration was 10 months. Another study by Ciruelos et al (2009) investigated the combination in the firstand second-line setting with a response rate of 61 and $48.5 \%$, respectively. Most frequent grade 3-4 observed toxic effects were neutropenia (60\%) and hand-foot syndrome (16\%). The authors concluded that the combination of GemCap is an active and safe regimen in anthracycline-pretreated breast cancer patients (Campos et al, 2001; Schilsky et al, 2001; Andres et al, 2005; Ciruelos et al, 2009; Malmstrom et al, 2010).

Taken together, these data provided the basis for this open, randomised phase II study, which investigated the efficacy of three different gemcitabine-based regimens for patients with MBC.

\section{PATIENTS AND METHODS}

\section{Patient population}

One-hundred and forty-one patients with histologically confirmed MBC were recruited on a treatment protocol approved by the independent ethics committees of all participating centres and was conducted according to the International Conference on Harmonisation (ICH) - Good Clinical Practice (GCP) guidelines. All patients were required to give written informed consent before study entry.

The study was registered by the US National Institutes of Health (http://clinicaltrials.gov/; ClinicalTrials.gov Identifier: NCT00480597).

Patients eligible for the trial required one previous anthracyclinebased regimen (in the adjuvant or in the metastatic setting). There was no limit on number of previous chemotherapy regimens (except gemcitabine-, vinorelbine-, cisplatin- or capecitabinecontaining regimens), or on the number of previous hormonal therapies. Moreover, immunotherapy or local radiotherapy was allowed. Patients were required to have at least one bi-dimensionally measurable lesion outside a previous radiation port. Other eligibility criteria included age $\geqslant 18$ and $\leqslant 70$ years, Karnofsky performance status $\geqslant 70 \%$, minimal life expectancy of 12 weeks, and adequate haematological, renal, cardiac and hepatic function (leukocyte count $\geqslant 3.0 \times 10^{9} 1^{-1}$ or absolute neutrophil count $\geqslant 2 \times 10^{9} 1^{-1}$; platelet count $\geqslant 100 \times 10^{9} \mathrm{l}^{-1}$; haemoglobin $\geqslant 8 \mathrm{~g} \mathrm{dl}^{-1}$; total serum bilirubin $\leqslant 1.25 \times$ upper limit of normal (ULN) in the absence of liver metastasis or $\leqslant 3.0 \times$ ULN in the presence of liver metastasis; transaminase (ALT, AST) level $\leqslant 3 \times$ ULN in the absence of liver metastasis or $\leqslant 5 \times$ ULN in the presence of liver metastasis; and alkaline phosphatase level $\leqslant 2.5 \times \mathrm{ULN}$ ). Creatinine clearance was required to exceed $60 \mathrm{ml} \mathrm{min}^{-1}$.

Patients were not eligible for study enrolment if they were pregnant, lactating or refused effective contraception, if they had bone metastasis only, known brain metastases or a secondary malignancy, history of another primary malignant disease other than in situ carcinoma of the uterine cervix or adequately treated basal cell skin cancer, active infection or any other concomitant severe clinical condition making implementation of the protocol including prehydration difficult. Administration of other cytotoxic, immune or hormonal agents or radiation therapy was not permitted during the study, with the exception of contraceptives, corticosteroids given as antiemetic treatment, or local palliative radiation. Patients were not eligible if they had received prior gemcitabine, vinorelbine, cisplatin or capecitabine. Finally, patients with a history of DPD-deficiency were ineligible for the trial.

\section{Patient assessment}

Patients were evaluated on a regular basis during treatment. The following assessments were performed before each 3-week cycle: physical examination, complete blood count, serum chemistry (including creatinine clearance) and assessment of toxicities. During the initial phase of treatment, complete blood counts were performed twice weekly to determine the nadir values. If the haematological values had not recovered by the time of scheduled treatment, the complete blood count was repeated every week until recovery of leukocyte count to $3.0 \times 10^{9} 1^{-1}$ and platelets to $\geqslant 100 \times 10^{9} 1^{-1}$.

Baseline tumour assessment was performed within 2 weeks of the start of treatment using imaging procedures, such as ultrasound, computerised tomography or magnetic resonance imaging. Tumour assessments were repeated after every three cycles of therapy, applying the initially used imaging procedure. World Health Organization and NCN-CTC criteria (3.0) were used for the assessment of tumour response and toxicity grading (Ajani et al, 1990).

In addition, time to response (time from the start of therapy to first documentation of objective response), duration of response (time from the first documentation of objective response to first evidence of progressive disease), time to tumour progression (time from the start of therapy to first evidence of progressive disease or last follow-up) and survival (time from the start of therapy to death) were measured (intent to treat).

\section{Treatment schedule}

Patients were randomly assigned to one of the following treatment schedules:

1. Gemcitabine $1000 \mathrm{mg} \mathrm{m}^{-2}$ (soluted in $250 \mathrm{ml}$ of $0.9 \%$ saline) given as a 30 -min infusion on days $1+8$ followed by vinorelbine $25 \mathrm{mg} \mathrm{m}^{-2}$ (soluted in $100 \mathrm{ml}$ of $0.9 \%$ saline) given as a $6-10 \mathrm{~min}$ infusion on days $1+8$ of a 3 -week treatment cycle.

2. Gemcitabine $1000 \mathrm{mg} \mathrm{m}^{-2}$ (soluted in $250 \mathrm{ml}$ of $0.9 \%$ saline) given as a 30 -min infusion on days $1+8$ plus cisplatin $30 \mathrm{mg} \mathrm{m}^{-2}$ (soluted in $500 \mathrm{ml}$ of $0.9 \%$ saline) given as a 60 -min infusion on days $1+8$ of a 3 -week treatment cycle. Patients within this treatment arm received pre- and posthydration with $1 \mathrm{~lm}^{-2} 0.9 \%$ saline i.v. over $2 \mathrm{~h}$ or orally $2-3 \mathrm{l}$ mineral water over $8 \mathrm{~h}$. Immediately prior to cisplatin $20 \mathrm{mg}$ of furosemide was applied by i.v. injection.

3. Gemcitabine $1000 \mathrm{mg} \mathrm{m}^{-2}$ (soluted in $250 \mathrm{ml}$ of $0.9 \%$ saline) given as a 30 -min infusion on days $1+8$ plus capecitabine $1.300 \mathrm{mg} \mathrm{m}^{-2}$ (divided in 2 daily doses) given orally on days $1-14$ of a 3-week treatment cycle.

All patients received antiemetics (mainly 5- $\mathrm{HT}_{3}$ antagonists) according to the local standards. Patients within the cisplatin regimen were allowed to receive corticosteroids also.

Treatment was continued until disease progression or the occurrence of unacceptable toxicity. In case of a partial response or stable disease a maximum of 6 cycles were planned. If patients 
achieved a complete remission, two additional cycles were allowed ( $\mathrm{CR}+2$ cycles; maximum 8 cycles).

\section{Dose adjustments}

Dose adjustments were made on the basis of leukocyte and platelet counts on the day of treatment and clinical assessments of nonhaematological toxicities.

A full dose was applied when the leukocyte count was $>2.5 \times 10^{9} \mathrm{l}^{-1}$, while the platelet count exceeded $100 \times 10^{9} 1^{-1}$; the doses of both drugs were reduced by $25 \%$ if the leukocyte count was between 2.0 and $2.5 \times 10^{9} 1^{-1}$, while the platelet count exceeded $100 \times 10^{9} 1^{-1}$; and if the leukocyte count was $<2.0 \times 10^{9} 1^{-1}$ or the platelet count $<100 \times 10^{9} 1^{-1}$, the doses of both drugs were omitted. Omitted day- 8 doses were not replaced and the next cycle was given timely as scheduled but at reduced doses. If the patient tolerated the dose-modified treatment well, a re-increase of dosage could be attempted in the following cycle. The use of haematopoietic growth factors was allowed in patients with prolonged haematopoietic recovery. If any grade 3 toxicity except nausea/vomiting occurred, drug doses were reduced by $50 \%$; while the patient was out of study in case of any grade 4 nonhaematological toxicity. A full dose was applied if any grade 0-2 toxicity except nausea/vomiting (grade 3 ) occurred.

Patients who were randomised to cisplatin were required to have a creatinine clearance, which exceeds $60 \mathrm{ml} \mathrm{min}^{-1}$ during treatment, otherwise they were out of study. Creatinine clearance was estimated according to the recommendation of the "National Kidney Disease Education Program' and the 'Modification of Diet in Renal Diseasestudy'. The glomerular filtration rate (GFR) was calculated by the MDRD formula: GFR (ml per $\min$ per $\left.1.73 \mathrm{~m}^{2}\right)=186 \times \mathrm{C}^{-1.154}$ $\left(\mathrm{mg} \mathrm{dl}^{-1}\right) \times \mathrm{age}^{-0.203}$ (years) $\times k ; \mathrm{C}=$ serum creatinine concentration; $k=$ correction factor (female 0.742 ; male 1.0 ).

\section{Biometrical analysis}

The primary objective of the study was to determine the objective response rate to the study treatment. Secondary end points included time to progression, survival and toxicity.

Simon's optimal two-stage design was used to ensure that the number of patients exposed to this therapy was minimised should the therapy prove ineffective (Simon, 1989). The study was planned to distinguish between a clinically uninteresting response rate of $20 \%$ (null hypothesis) and a clinically interesting response rate of $40 \%$ (alternative hypothesis). With the type I error being $5 \%$ and the type II error $10 \%, 13$ patients were to be enrolled during the first step and an additional 30 patients during the second step. If three or less responses occurred among the first 13 patients or 12 or less responses in the total population of 43 patients, the treatment had to be judged ineffective and enrolment stopped. Assuming a dropout rate of $10 \%$, it was planned to enrol a total of 47 patients on each treatment arm $(3 \times 47=141$ patients $)$.

The determination of the $95 \%$ confidential intervals (CIs) resulted by the exact method of Clopper/Pearson.

Time-to-event end points were calculated according to the method of Kaplan and Meier (1959). Patients who received at least one treatment cycle were evaluable for toxicity, and those who had received at least two treatment cycles or those who progressed after the first cycle were evaluable for response.

\section{RESULTS}

\section{Patient characteristics}

One-hundred and forty-one eligible patients were recruited between 2003 and 2006 from 24 German centres. Because of protocol violation in six cases (inclusion criteria) and one written informed consent refusal, a total of 134 patients were evaluated for the primary end point (Figure 1).

Median age was 58 years (GemVin), 60 years (gemcitabine plus cisplatin, GemCis) and 60 years (GemCap), respectively. All patients had previously received prior anthracyclines either in the (neo-)adjuvant or the metastatic setting. Approximately $40 \%$ of the patients had received both, an anthracycline- and a taxanebased regimen. Moreover, a majority of the patients presented with visceral metastases $(>80 \%)$ and $\sim 75 \%$ had more than one metastatic site. About a third of the patients received the study medication as first-line regimen for metastatic disease.

Detailed demography and baseline characteristics are shown in Table 1.

\section{Treatment delivery}

In total, 200 cycles of GemVin, 190 cycles of GemCis and 207 cycles of GemCap were applied. Patients received a median number of 6 cycles (GemVin), 4.5 cycles (GemCis) and 5 cycles (GemCap). Dose reductions and delays were not significantly different among the treatment arms. An increased rate of day- 8 omissions contributed to a significantly lower relative dose intensity within the cisplatin combination $(81.3 \%)$ compared with $94 \%$ within the capecitabine regimen (relative dose intensity, significance test $\chi^{2}$ for all arms, $P=0.003$; vinorelbine $v s$ cisplatin, $P=0.45$; vinorelbin $v s$ capecitabine, $P=0.14$; cisplatin $v s$ capecitabine, $P=0.0003$ ).

Detailed information regarding medication is given in Table 2.

\section{Efficacy - response and survival}

With a response rate of $39.0 \%$, 95\% CI: $24.2-55.5$ (GemVin); 47.7\%, 95\% CI: 32.5-63.3 (GemCis); and 34.7\%, 95\% CI: 21.7-49.6 (GemCap), there was no striking difference regarding the primary objective among the three study arms. Overall, the disease control rate (objective response plus stable disease) was $63.4 \%$ (GemVin), $56.8 \%$ (GemCis) and 59.2\% (GemCap), respectively (Table 3).

A detailed analysis of response with regard to triple negative patients was undertaken. The corresponding response rates were 11.1\%, 95\% CI: $0.3-48.3$ (GemVin); 58.3\%, 95\% CI: $27.7-84.8$ (GemCis); and 53.3\%, 95\% CI: 27.0-78.7 (GemCap).

The median follow-up interval for the whole study population was 11.1 months (95\% CI: 7.6-14.6 months). Median duration of response was 6.9 months, 95\% CI: 5.1-8.1 (GemVin); 6.9 months, 95\% CI: 5.5-8.8 (GemCis); and 8.3 months, 95\% CI: 7.1-10.6

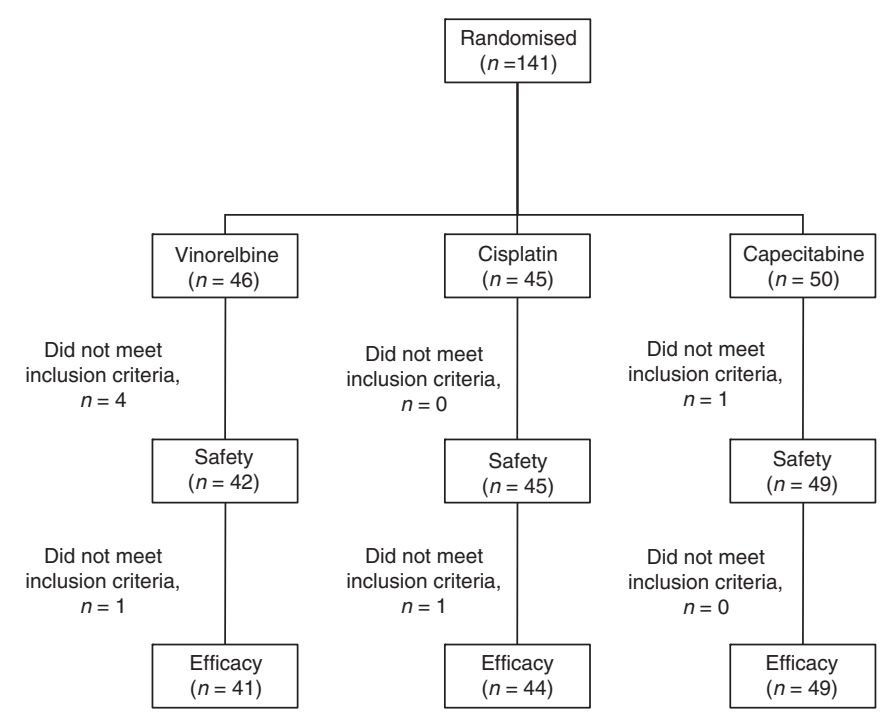

Figure I Flow of participants. 
Table I Patients demography and characteristics

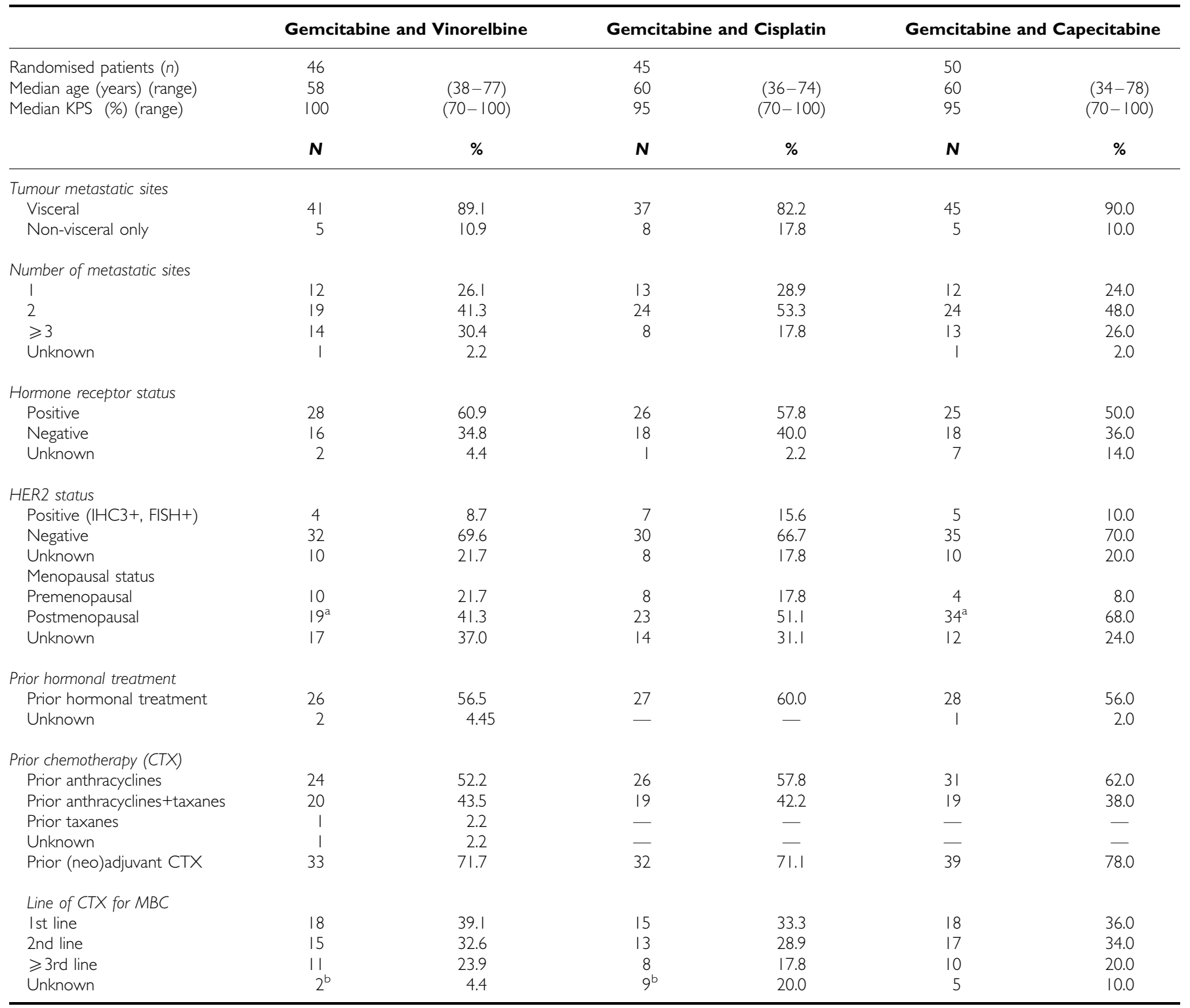

Abbreviations: FISH = fluorescence in situ hybridisation; HER2 = human epidermal growth factor receptor 2; $1 \mathrm{HC} 3+=$ immunohistochemistry $(\mathrm{DAKO} 3+$ ); KPS = Karnofsky performance scale; $M B C=$ metastatic breast cancer. ${ }^{a}$ Statistical significant $(P=0.01)$. ${ }^{b}$ Statistical significant $(P=0.03)$.

(GemCap). The median progression-free survival was 5.7 months, 95\% CI: 3.9-8.2 (GemVin); 6.9 months, 95\% CI: 5.8-8.8 (GemCis); and 8.3 months, 95\% CI: 4.3-9.6 (GemCap), and the median overall survival was estimated with 17.5 months, $95 \% \mathrm{CI}: 12.2-30.0$ (GemVin); 13.0 months, 95\% CI: $11.0-19.2$ (GemCis); and 19.4 months, 95\% CI: 16.6-22.0 (GemCap).

Progression-free and overall survival curves are shown in Figures 2 and 3.

\section{Toxicity}

The predominant haematological toxicity was grade 3-4 neutropenia, which occurred in $16.6 \%$ of the patients within the GemVin arm. This was significantly higher compared with the rate of neutropenia within the GemCap arm $(0 \% ; P=0.004)$. Moreover, only $4.4 \%$ of the patients who received the cisplatin combination experienced grade 3-4 neutropenia. Febrile neutropenia was observed in none of the included patients. The rate of grade
3 and 4 anaemia and thrombopenia was low and comparable within the treatment arms.

Non-haematological toxicity was considered mild to moderate. Grade 3 and 4 non-haematological toxicity was observed in few patients including hand-foot syndrome $(2 \%)$ and dermatological side effects $(4.1 \%)$, predominantly in those patients who received capecitabine. Any other non-haematological toxicity was comparable among the study population.

Detailed information of haematological and non-haematological toxicity is given in Table 4 .

\section{DISCUSSION}

With the increasing use of anthracycline- and taxane-based regimens in the neoadjuvant and adjuvant setting and their established application in the treatment of the advanced and metastatic stages of breast cancer, there is a clear need for noncross-resistant further-line regimens. 
Table 2 Medication, dose adjustments and delays

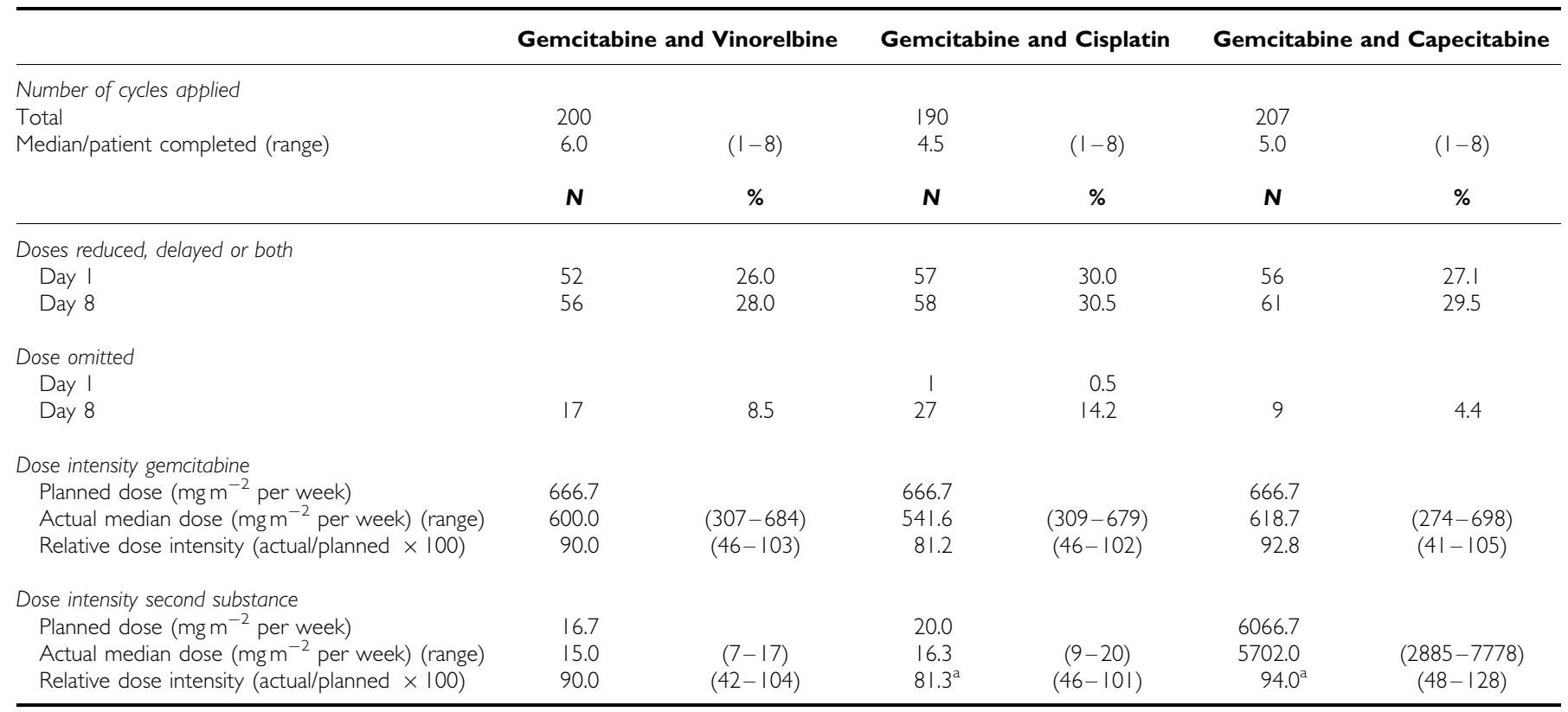

${ }^{a}$ Statistical significant $(P=0.0003)$ by Fishers exact test.

Table 3 Efficacy - response rates

\begin{tabular}{|c|c|c|c|c|c|c|c|c|c|}
\hline & \multicolumn{3}{|c|}{ Gemcitabine and Vinorelbine } & \multicolumn{3}{|c|}{ Gemcitabine and Cisplatin } & \multicolumn{3}{|c|}{ Gemcitabine and Capecitabine } \\
\hline & $\mathbf{N}$ & $\%$ & $95 \% \mathrm{Cl}$ & $\mathbf{N}$ & $\%$ & $95 \% \mathrm{Cl}$ & $\mathbf{N}$ & $\%$ & $95 \% \mathrm{Cl}$ \\
\hline PR & 13 & 31.7 & $18.1-48.1$ & 17 & 38.6 & $24.4-54.5$ & 13 & 26.5 & $|5.0-4| . \mid$ \\
\hline ORR & 16 & 39.0 & $24.2-55.5$ & 21 & 47.7 & $32.5-63.3$ & 17 & 34.7 & $21.7-49.6$ \\
\hline SD & 10 & 24.4 & $12.4-40.3$ & 4 & 9.1 & $2.5-21.7$ & 12 & 24.5 & $13.3-38.9$ \\
\hline PD & II & 26.8 & $14.2-42.9$ & 11 & 25.0 & $13.2-40.3$ & 12 & 24.5 & $13.3-38.9$ \\
\hline
\end{tabular}

Abbreviations: $\mathrm{Cl}=$ confidence interval; $\mathrm{CR}=$ complete remission; $\mathrm{NE}=$ not evaluable by Fishers exact test; $\mathrm{ORR}=$ overall response rate; $\mathrm{PD}=$ progressive disease; $\mathrm{PR}=$ partial response; $\mathrm{SD}=$ stable disease.

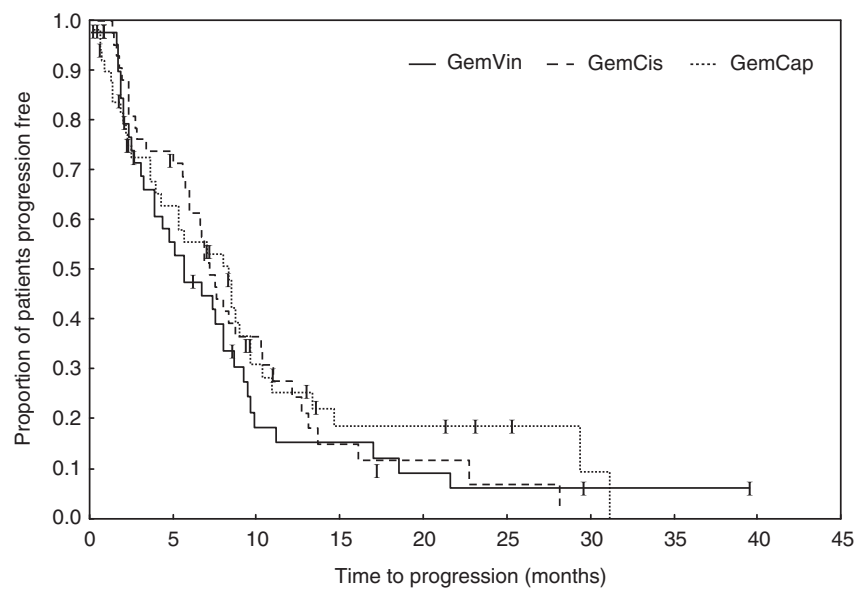

Figure 2 Progression-free survival.

While there is no established standard of chemotherapy for anthracycline- and taxane-pretreated patients, capecitabine has become a widely accepted agent in this setting. Response rates in the range of $26-52 \%$ and time to progression of $3.6-8.9$ months were reported in numerous phase II and III trials (Oshaughnessy

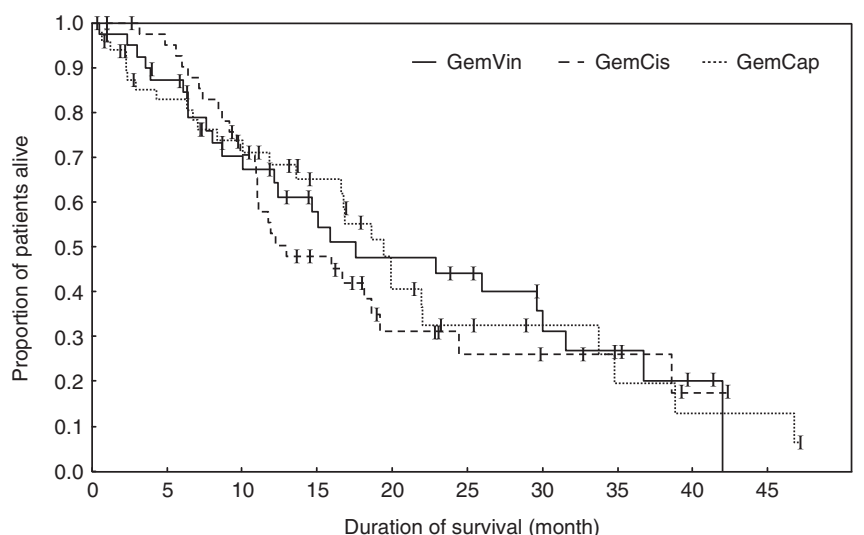

Figure 3 Overall survival.

et al, 2001; Ahn et al, 2004; Batista et al, 2004; Lee et al, 2004; Wist et al, 2004). The combination of GemCap was investigated in some small phase II studies. Patients who had received that combination as first-line regimen for $\mathrm{MBC}$ experienced a high response rate of $61 \%$, whereas the response rate was $41-48.7 \%$ for those who had already received anthracyclines and/or taxanes for metastatic disease (Andres et al, 2005; Ciruelos et al, 2009; Malmstrom et al, 
Table 4 Adverse reactions, per-patient-analysis, toxicity grade $\geqslant 3$

\begin{tabular}{|c|c|c|c|c|c|c|c|c|c|}
\hline & \multicolumn{2}{|c|}{$\begin{array}{c}\text { Gem/Vin toxicity } \\
\text { grade } \geqslant 3\end{array}$} & \multicolumn{2}{|c|}{$\begin{array}{c}\text { Gem/Cis toxicity } \\
\text { grade } \geqslant 3\end{array}$} & \multicolumn{2}{|c|}{$\begin{array}{c}\text { Gem/Cap toxicity } \\
\text { grade } \geqslant 3\end{array}$} & \multirow{2}{*}{$\begin{array}{c}\text { Gem/Vin vs } \\
\text { Gem/Cis } \\
P \text {-value }\end{array}$} & \multirow{2}{*}{$\begin{array}{c}\text { Gem/Vino vs } \\
\text { Gem/Cap } \\
\text { P-value }\end{array}$} & \multirow{2}{*}{$\begin{array}{c}\text { Gem/Cis vs } \\
\text { Gem/Cap } \\
\text { P-value }\end{array}$} \\
\hline & $\mathbf{N}$ & $\%$ & $\mathbf{N}$ & $\%$ & $\mathbf{N}$ & $\%$ & & & \\
\hline \multicolumn{10}{|l|}{ Haematologic } \\
\hline $\begin{array}{l}\text { Neutropenia } \\
\text { Febrile neutropenia }\end{array}$ & 7 & 16.7 & 2 & 4.4 & & & 0.07 & 0.004 & 0.49 \\
\hline Anaemia & 1 & 2.4 & 4 & 8.9 & I & 2.0 & 0.36 & 1 & 0.19 \\
\hline \multicolumn{10}{|l|}{$\begin{array}{l}\text { Non-haematological } \\
\text { Alopaecia } \\
\text { Fatigue }\end{array}$} \\
\hline Nausea & 2 & 4.8 & 2 & 4.4 & 2 & 4.1 & 1 & 1 & 1 \\
\hline $\begin{array}{l}\text { Vomiting } \\
\text { Mucositis } \\
\text { Constipation }\end{array}$ & I & 2.4 & 3 & 6.7 & 3 & 6.1 & 0.62 & 0.62 & i \\
\hline Bone pain & । & 2.4 & & & & & 0.48 & 0.46 & 1 \\
\hline $\begin{array}{l}\text { Dyspnoea } \\
\text { Abdominal pain }\end{array}$ & । & 2.4 & 5 & 11.1 & 2 & 4.1 & 0.20 & I & 0.25 \\
\hline $\begin{array}{l}\text { Oedema } \\
\text { Rash }\end{array}$ & & & & & । & 2.0 & I & । & 1 \\
\hline Hand-foot syndr. & & & & & । & 2.0 & I & 1 & I \\
\hline $\begin{array}{l}\text { Dermatology } \\
\text { Creatinine } \\
\text { ALT (GPT) }\end{array}$ & & & & & 2 & 4.1 & I & 0.5 & 0.5 \\
\hline AST (GOT) & & & & & 3 & 6.1 & । & 0.25 & 0.24 \\
\hline AP & । & 2.4 & & & । & 2.0 & 0.48 & I & I \\
\hline Bilirubin & & & & & । & 2.0 & I & 0.48 & । \\
\hline
\end{tabular}

Abbreviations: $\mathrm{ALT}=$ alanine transaminase; $\mathrm{AP}=$ alkaline phosphatase; $\mathrm{AST}=$ aspartate transaminase; $\mathrm{GOT}=$ glutamate oxalacitate transaminase; $\mathrm{GPT}=$ glutamate pyruvate transaminase; $\mathrm{MOT}=$ motoric. $P$-values are calculated by Fishers exact test.

2010). With regard to pretreatment, the response rate of $34.7 \%$ (95\% CI: 21.7-49.6) within the present trial seems to be comparable with these data. The good tolerability of this regimen was documented by the absence of severe neutropenia (grade 3-4 $0 \%)$ and the low rate of severe hand-foot syndrome $(2.0 \%)$. Discrepancies regarding the toxicity profile are partly explained by differences within the schedules, as previous investigators reported severe neutropenia in up to $60 \%$ of the patients and a consistent rate of hand-foot syndrome of about 15\% (Andres et al, 2005; Ciruelos et al, 2009; Malmstrom et al, 2010).

The preclinical rationale for a combination of gemcitabine with a platinum analogue is supported by the synergistic interaction of both agents (Peters et al, 1995; van Moorsel et al, 1997; Achanta et al, 2001). Several clinical studies performed with various schedules have demonstrated that the combination of gemcitabine and platin is highly active not only in first-line treatment, but also in patients previously exposed to anthracyclines and/or taxanes (Nagourney et al, 2004, 2008; Nasr et al, 2004; Silva et al, 2004; Alauddin and Shaharyar, 2005; Burch et al, 2005; Stemmler et al, 2005; Chitapanarux et al, 2006; Demiray et al, 2006; Fuentes et al, 2006; Heinemann et al, 2006; Yardley et al, 2006; Laessig et al, 2007; Moura et al, 2007; Seo et al, 2007; Kim et al, 2008; Loesch et al, 2008; Chew et al, 2009; Somali et al, 2009). The remission rate of the combination in the present trial was $47.7 \%$ (95\% CI: 32.5-63.3), which compared favourably to reported remission rates of $21.5-69.2 \%$ in the first- and second-line setting published by other investigators (Nagourney et al, 2004, 2008; Nasr et al, 2004; Silva et al, 2004; Alauddin and Shaharyar, 2005; Burch et al, 2005; Stemmler et al, 2005; Chitapanarux et al, 2006; Demiray et al, 2006; Fuentes et al, 2006; Heinemann et al, 2006; Yardley et al, 2006; Laessig et al, 2007; Moura et al, 2007; Seo et al,
2007; Kim et al, 2008; Loesch et al, 2008; Chew et al, 2009; Somali et al, 2009). As reported by Koshy et al (2010), the schedule has proven sustained efficacy with a response rate of $58.3 \%$ (95\% CI: 27.7-84.8) even in those with triple-negative breast cancer (TNBC). This finding seems to be reaffirmed in the present trial with a response rate of $58.3 \%$ (95\% CI: 27.7-84.8) in the subgroup of TNBC patients. Regarding treatment-associated toxicity, GemCis must be considered as well tolerable. Compared with previously reported studies, the rate of severe (grade 3 and 4) neutropenia and thrombocytopenia was rather low in our study with 4.4 and $6.7 \%$, respectively.

Finally, the study arm of GemVin within this study yielded a response rate of $39.0 \%$ (95\% CI: $24.2-55.5$ ), which is also in a range previously published in pretreated patients with $\mathrm{MBC}$ (22 -55.5\%; Haider et al, 1999; Nicolaides et al, 2000; Valenza et al, 2000; Stathopoulos et al, 2002; Park et al, 2009; Shehata et al, 2010). Comparably to those studies, the main side effect was grade 3 and 4 neutropenia, but the incidence was considerably lower in our trial (present trial: 16.7, $0 \%$ febrile neutropenia $v s$ literature: $42-48 \%$, up to $11 \%$ febrile neutropenia). Non-haematological toxicity was generally mild, but included grade 3 and 4 nausea and vomiting in few patients with 4.8 and $2.4 \%$, respectively.

In summary, there was no striking difference with regard to any efficacy parameter in terms of response rate, progression-free or overall survival. These results compared favourably with those published by other investigators (Nicolaides et al, 2000; Mohran, 2004; Alauddin and Shaharyar, 2005; Andres et al, 2005; Burch et al, 2005; Stemmler et al, 2005; Demiray et al, 2006; Fuentes et al, 2006; Heinemann et al, 2006; Moura et al, 2007; Seo et al, 2007; Kim et al, 2008; Chew et al, 2009; Ciruelos et al, 2009; Park et al, 2009; Somali et al, 2009; Koshy et al, 2010; 
Shehata et al, 2010). It is important to point out that efficacy is maintained particularly in patients with TNBC (Koshy et al, 2010). This applies in particular for the study arms containing cisplatin and capecitabine.

Besides a negligible decrease in dose intensity of the GemCis arm and a slightly increased rate of grade 3 and 4 neutropenia, the toxicity profile among the three study arms seems comparable. None of the recruited patients developed febrile neutropenia, which emphasises the tolerability of the schedules. Comparing all the toxicities that occurred within the present trial with previously published trials that investigated one of the combinations for MBC, there are some strong distinctions regarding the toxicity profile and in particular the rate of severe neutropenia. These discrepancies are partly explained by differences within the doses that

\section{REFERENCES}

Achanta G, Pelicano H, Feng L, Plunkett W, Huang P (2001) Interaction of p53 and DNA-PK in response to nucleoside analogues: potential role as a sensor complex for DNA damage. Cancer Res 61: 8723-8729

Ahn JH, Kim SB, Kim TW, Ahn SH, Kim SM, Park JM, Lee JS, Kang YK, Kim WK (2004) Capecitabine and vinorelbine in patients with metastatic breast cancer previously treated with anthracycline and taxane. J Korean Med Sci 19: $547-553$

Ajani JA, Welch SR, Raber MN, Fields WS, Krakoff IH (1990) Comprehensive criteria for assessing therapy-induced toxicity. Cancer Invest 8: 147 - 159

Alauddin A, Shaharyar A (2005) Gemcitabine and cisplatin combination chemotherapy as first-line treatment in patients with metastatic breast cancer. J Clin Oncol, ASCO Annu Meeting Proc (Post-Meeting Edition) 23: abstract 713

Andres R, Mayordomo JI, Lara R, Lastra R, Ortega E, Polo E, Lambea J, Isla D, Saenz-Cusi A, Escudero P, Tres A (2005) Gemcitabine/ capecitabine in patients with metastatic breast cancer pretreated with anthracyclines and taxanes. Clin Breast Cancer 6: 158-162

Batista N, Perez-Manga G, Constenla M, Ruiz A, Carabantes F, Castellanos J, Gonzalez Baron M, Villman K, Soderberg M, Ahlgren J, Casinello J, Regueiro P, Murias A (2004) Phase II study of capecitabine in combination with paclitaxel in patients with anthracycline-pretreated advanced/metastatic breast cancer. Br J Cancer 90: 1740 - 1746

Blackstein M, Vogel CL, Ambinder R, Cowan J, Iglesias J, Melemed A (2002) Gemcitabine as first-line therapy in patients with metastatic breast cancer: a phase II trial. Oncology 62: 2-8

Brodowicz T, Kostler WJ, Moslinger R, Tomek S, Vaclavik I, Herscovici V, Wiltschke C, Steger GG, Wein W, Seifert M, Kubista E, Zielinski CC (2000) Single-agent gemcitabine as second- and third-line treatment in metastatic breast cancer. Breast 9: 338-342

Burch PA, Mailliard JA, Hillman DW, Perez EA, Krook JE, Rowland KM, Veeder MH, Cannon MW, Ingle JN (2005) Phase II study of gemcitabine plus cisplatin in patients with metastatic breast cancer: a North Central Cancer Treatment Group Trial. Am I Clin Oncol 28: 195-200

Campos LT, Alvarez RH, Sanford DB (2001) Gemcitabine and Capecitabine in advanced pancreatic cancer and solid tumors: a sigle institution experience. Proc Am Soc Clin Oncol 20: abstract \#2315

Chew HK, Doroshow JH, Frankel P, Margolin KA, Somlo G, Lenz HJ, Gordon M, Zhang W, Yang D, Russell C, Spicer D, Synold T, Bayer R, Hantel A, Stiff PJ, Tetef ML, Gandara DR, Albain KS (2009) Phase II studies of gemcitabine and cisplatin in heavily and minimally pretreated metastatic breast cancer. J Clin Oncol 27: 2163-2169

Chitapanarux I, Lorvidhaya V, Kamnerdsupaphon P, Tharavichitkul E, Trakultivakorn H, Somwangprasert A, Sumitsawan S, Srisukho S, Watcharachan K, Sukthomya V (2006) Gemcitabine plus cisplatin (GC): a salvage regimen for advanced breast cancer patients who have failed anthracycline and/or taxane therapy. Gan To Kagaku Ryoho 33: $761-766$

Ciruelos EM, Cortes J, Cortes-Funes H, Mayordomo JI, Bermejo B, Ojeda B, Garcia E, Rodriguez CA, Munoz M, Gomez P, Manso L, Andres R, Lluch A, Saura C, Mendiola C, Baselga J (2009) Gemcitabine and capecitabine in previously anthracycline-treated metastatic breast cancer: a multicenter phase II study (SOLTI 0301 trial). Ann Oncol 21(7): 1442 - 1447 were applied in these trials. Therefore, drawing a final conclusion outside a comparative trial is virtually impossible.

In conclusion, this randomised phase II trial has revealed comparable results for all three gemcitabine-based regimens regarding efficacy and toxicity. Gemcitabine-based chemotherapy appears to be a notable treatment option for pretreated patients with MBC.

\section{ACKNOWLEDGEMENTS}

This study was supported by Lilly GmbH Germany.

\section{Conflicts of interest}

The authors declare no conflict of interest.
Degardin M, Bonneterre J, Hecquet B, Pion JM, Adenis A, Horner D, Demaille A (1994) Vinorelbine (navelbine) as a salvage treatment for advanced breast cancer. Ann Oncol 5: 423-426

Demiray M, Evrensel T, Kanat O, Kurt E, Arslan M, Gokgoz S, Tolunay S, Manavoglu O (2006) Open labeled phase II observation study of gemcitabine plus cisplatin plus trastuzumab (GCT) in metastatic breast cancer patients with prior anthracyclines and taxanes exposures: Preliminary results. J Clin Oncol, ASCO Ann Meeting Proc (Post-Meeting Edition) 24: abstract 10720

Fuentes H, Calderillo G, Alexander F, Ramirez M, Avila E, Perez L, Aguirre G, Onate-Ocana LF, Gallardo D, Otero J (2006) Phase II study of gemcitabine plus cisplatin in metastatic breast cancer. Anticancer Drugs 17: $565-570$

Gregory RK, Smith IE (2000) Vinorelbine-a clinical review. Br J Cancer 82: $1907-1913$

Haider K, Kornek GV, Kwasny W, Weinlander G, Valencak J, Lang F, Puribauer F, Kovats E, Depisch D, Scheithauer W (1999) Treatment of advanced breast cancer with gemcitabine and vinorelbine plus human granulocyte colony-stimulating factor. Breast Cancer Res Treat 55: 203-211

Heinemann V (2003) Role of gemcitabine in the treatment of advanced and metastatic breast cancer. Oncology 64: 191-206

Heinemann V (2005) Gemcitabine in metastatic breast cancer. Expert Rev Anticancer Ther 5: 429-443

Heinemann V, Stemmler HJ, Wohlrab A, Bosse D, Losem C, Kahlert S, Rauthe G (2006) High efficacy of gemcitabine and cisplatin in patients with predominantly anthracycline- and taxane-pretreated metastatic breast cancer. Cancer Chemother Pharmacol 57: 640-646

Jones S, Winer E, Vogel C, Laufman L, Hutchins L, O’Rourke M, Lembersky B, Budman D, Bigley J, Hohneker J (1995) Randomized comparison of vinorelbine and melphalan in anthracycline-refractory advanced breast cancer. J Clin Oncol 13: 2567-2574

Kaplan EL, Meier P (1959) Nonparametric estimation from incomplete observations. J Am Stat Assoc 53: 457-481

Kim JH, Oh SY, Kwon HC, Lee S, Kim SH, Kim DC, Lee JH, Lee HS, Cho SH, Kim HJ (2008) Phase II study of gemcitabine plus cisplatin in patients with anthracycline- and taxane- pretreated metastatic breast cancer. Cancer Res Treat 40: $101-105$

Kolaric K, Vukas D (1991) Carboplatin activity in untreated metastatic breast cancer patients-results of a phase II study. Cancer Chemother Pharmacol 27: 409-412

Koshy N, Quispe D, Shi R, Mansour R, Burton GV (2010) Cisplatingemcitabine therapy in metastatic breast cancer: Improved outcome in triple negative breast cancer patients compared to non-triple negative patients. Breast 19: 246-248

Laessig D, Stemmler HJ, Vehling-Kaiser U, Fasching PA, Melchert F, Kolbl H, Stauch M, Maubach P, Scharl A, Morack G, Meerpohl H, Weber B, Kalischefski B, Heinemann V (2007) Gemcitabine and carboplatin in intensively pretreated patients with metastatic breast cancer. Oncology 73: $407-414$

Lee SH, Lee J, Park J, Park SH, Lee KE, Lee SI, Nam E, Park JO, Kim K, Jung CW, Park YS, Yoon SS, Kang WK, Lee MH, Park K, Im YH (2004) Capecitabine monotherapy in patients with anthracycline- and taxanepretreated metastatic breast cancer. Med Oncol 21: 223-231 
Loesch D, Asmar L, McIntyre K, Doane L, Monticelli M, Paul D, Vukelja S, Orlando M, Vaughn LG, Zhan F, Boehm KA, O'Shaughnessy JA (2008) Phase II trial of gemcitabine/carboplatin (plus trastuzumab in HER2positive disease) in patients with metastatic breast cancer. Clin Breast Cancer 8: 178-186

Malmstrom A, Hansen J, Malmberg L, Carlsson L, Svensson JH, Ahlgren J, Ahlin C, Jansson T, Westberg R (2010) Gemcitabine and capecitabine in combination for advanced anthracycline and taxane pre-treated breast cancer patients: A phase II study. Acta Oncol 49: $35-41$

Modi S, Currie VE, Seidman AD, Bach AM, Panageas KS, Theodoulou M, Moasser MM, D'Andrea GM, Lake DE, Choi J, Norton L, Hudis CA (2005) A phase II trial of gemcitabine in patients with metastatic breast cancer previously treated with an anthracycline and taxane. Clin Breast Cancer 6: $55-60$

Mohran TZ (2004) Gemcitabine and cisplatin combination chemotherapy as a first-line treatment in patients with metastatic breast cancer. J Egypt Natl Canc Inst 16: 8-14

Moura GL, Pasquini R, Frare A, Vianna K, Albini L, Padilha S (2007) Gemcitabine and cisplatin in metastatic breast cancer. J Clin Oncol, ASCO Annu Meeting Proc (Post-Meeting Edition) 25: abstract 1084

Nagourney RA, Flam M, Link J, Hager S, Blitzer J, Lyons W, Sommers BL, Evans S (2008) Carboplatin plus gemcitabine repeating doublet therapy in recurrent breast cancer. Clin Breast Cancer 8: 432-435

Nagourney RA, Link J, Sommers B, Lyons W, Blitzer J, Hager S, Flam M (2004) Carboplatin \& gemcitabine repeating doublet in recurrent breast cancer. J Clin Oncol, 2004 ASCO Annu Meeting Proc (Post-Meeting Edition) 22: 851

Nasr FL, Chahine GY, Kattan JG, Farhat FS, Mokaddem WT, Tueni EA, Dagher JE, Ghosn MG (2004) Gemcitabine plus carboplatin combination therapy as second-line treatment in patients with relapsed breast cancer. Clin Breast Cancer 5: 117-122: discussion 123-114

Nicolaides C, Dimopoulos MA, Samantas E, Bafaloukos D, Kalofonos C, Fountzilas G, Razi E, Kosmidis P, Pavlidis N (2000) Gemcitabine and vinorelbine as second-line treatment in patients with metastatic breast cancer progressing after first-line taxane-based chemotherapy: a phase II study conducted by the Hellenic Cooperative Oncology Group. Ann Oncol 11: 873-875

Oshaughnessy JA, Blum J, Moiseyenko V, Jones SE, Miles D, Bell D, Rosso R, Mauriac L, Osterwalder B, Burger HU, Laws S (2001) Randomized, open-label, phase II trial of oral capecitabine (Xeloda) vs a reference arm of intravenous CMF (cyclophosphamide, methotrexate and 5-fluorouracil) as first-line therapy for advanced/metastatic breast cancer. Ann Oncol 12: $1247-1254$

Park IH, Ro J, Lee KS, Kim SN, Yun YH, Nam BH (2009) Phase II study of gemcitabine in combination with vinorelbine versus gemcitabine followed by vinorelbine for metastatic breast cancer. Invest New Drugs 28(5): $659-669$
Peters GJ, Bergman AM, Ruiz van Haperen VW, Veerman G, Kuiper CM, Braakhuis BJ (1995) Interaction between cisplatin and gemcitabine in vitro and in vivo. Semin Oncol 22: $72-79$

Schilsky RL, Bertucci D, Vogelzang NJ (2001) A dose escalating study of capecitabine plus gemcitabine in patients with advanced cancer. Proc Am Soc Clin Oncol 20: abstract 369

Seo JH, Oh SC, Choi CW, Kim BS, Shin SW, Kim YH, Kim JS, Kim AR, Lee JB, Koo BH (2007) Phase II study of a gemcitabine and cisplatin combination regimen in taxane resistant metastatic breast cancer. Cancer Chemother Pharmacol 59: 269-274

Shehata S, Saad E, Goda Y, El-Mesidi S, Koheil H, Elzawhri H, Kandeel A, Abdelhamid T, Zaki M, Meshref M (2010) A phase II study of gemcitabine combined with vinorelbine as first-line chemotherapy for metastatic breast cancer. Hematol Oncol Stem Cell Ther 3: 1-6

Silva JA, Perez Michel LM, Gallardo Rincon D (2004) Gemcitabine plus carboplatin in recurrent and advanced breast cancer: A phase II trial J Clin Oncol, ASCO Annu Meeting Proc (Post-Meeting Edition) 22: 877

Simon R (1989) Optimal two-stage designs for phase II clinical trials. Control Clin Trials 10: $1-10$

Somali I, Alacacioglu A, Tarhan MO, Meydan N, Erten C, Usalp S, Yilmaz U (2009) Cisplatin plus gemcitabine chemotherapy in taxane/anthracycline-resistant metastatic breast cancer. Chemotherapy 55: 155-160

Spielmann M, Llombart-Cussac A, Kalla S, Espie M, Namer M, Ferrero JM Dieras V, Fumoleau P, Cuvier C, Perrocheau G, Ponzio A, Kayitalire L, Pouillart P (2001) Single-agent gemcitabine is active in previously treated metastatic breast cancer. Oncology 60: 303-307

Stathopoulos GP, Rigatos SK, Pergantas N, Tsavdarides D, Athanasiadis I, Malamos NA, Stathopoulos JG (2002) Phase II trial of biweekly administration of vinorelbine and gemcitabine in pretreated advanced breast cancer. J Clin Oncol 20: $37-41$

Stemmler HJ, Kahlert S, Brudler O, Beha M, Muller S, Stauch B, Heinemann V (2005) High efficacy of gemcitabine and cisplatin plus trastuzumab in patients with HER2-overexpressing metastatic breast cancer: a phase II study. Clin Oncol (R Coll Radiol) 17: 630-635

Valenza R, Leonardi V, Gebbia V, Agostara B (2000) Gemcitabine and vinorelbine in pretreated advanced breast cancer: a pilot study. Ann Oncol 11: $495-496$

van Moorsel CJ, Veerman G, Bergman AM, Guechev A, Vermorken JB, Postmus PE, Peters GJ (1997) Combination chemotherapy studies with gemcitabine. Semin Oncol 24(2 Suppl 7): S7-17-S17-23 (Review)

Wist EA, Sommer HH, Ostenstad B, Risberg T, Bremnes Y, Mjaaland I (2004) Oral capecitabine in anthracycline- and taxane-pretreated advanced/metastatic breast cancer. Acta Oncol 43: 186-189

Yardley DA, Peacock N, Shipley D, Waterhause D, Landgdon R, Simons L, Thomas S, Hainsworth JD, Spigel DR, Burris HA (2006) Phase II trial of gemcitabine and carboplatin, plus trastuzumab in HER2+ patients as first line therapy in metastatic breast cancer. J Clin Oncol, ASCO Annu Meeting Proc (Post-Meeting Edition) 24: abstract no. 10590 